\title{
Structure and Thermoelectric Properties of New Layered Compounds in the Quaternary System Cs-Pb-Bi-Te
}

\author{
Kuei-Fang Hsu ${ }^{a}$, Duck-Young Chung ${ }^{a}$, Sangeeta Lal ${ }^{b}$, Tim Hogan ${ }^{b}$ and Mercouri G. Kanatzidis ${ }^{a}$ \\ ${ }^{a}$ Department of Chemistry and Center for Fundamental Materials Research, Michigan State \\ University, East Lansing, MI 48824, USA \\ ${ }^{b}$ Department of Electrical and Computer Engineering, Michigan State University, East Lansing, MI \\ 48824, USA
}

\begin{abstract}
By introducing of various equivalents of $\mathrm{PbTe}$ into the layered framework of $\mathrm{CsBi}_{4} \mathrm{Te}_{6}$, the four new compounds $\mathrm{CsPbBi}_{3} \mathrm{Te}_{6}(\mathbf{1}), \mathrm{CsPb}_{2} \mathrm{Bi}_{3} \mathrm{Te}_{7}(\mathbf{2}), \mathrm{CsPb}_{3} \mathrm{Bi}_{3} \mathrm{Te}_{8}(\mathbf{3})$ and $\mathrm{CsPb}_{4} \mathrm{Bi}_{3} \mathrm{Te}_{9}$ (4), were discovered. The compounds adopt layered structures built up of anionic slabs of progressively increasing thickness. The $\left[\mathrm{Pb}_{\mathrm{m}} \mathrm{Bi}_{3} \mathrm{Te}_{5+\mathrm{m}}\right]^{-}(\mathrm{m}=1,2,3,4)$ slabs in the four structures can be viewed as fragments excised from the PbTe-type structures with 4-, 5-, 6- and 7-monolayers, respectively. As prepared, these materials are off-stoichiometric and n-type conductors. We present preliminary results of the crystal structures and thermoelectric properties of these materials and classify them as members of the new homologous series $\mathrm{CsPb}_{\mathrm{m}} \mathrm{Bi}_{3} \mathrm{Te}_{5+\mathrm{m}}(\mathrm{m}=1$ to 4$)$.
\end{abstract}

\section{INTRODUCTION}

The incorporation of alkaline or alkaline earth cations into the $\mathrm{Bi}_{2} \mathrm{Q}_{3}(\mathrm{Q}=\mathrm{Se}, \mathrm{Te})$ lattice led to many new phases such as $\alpha-, \beta-\mathrm{K}_{2} \mathrm{Bi}_{8} \mathrm{Se}_{13}[1,2], \mathrm{K}_{2.5} \mathrm{Bi}_{8.5} \mathrm{Se}_{14}$ [2], $\mathrm{BaBiTe}_{3}$ [3], $\mathrm{CsBi}_{4} \mathrm{Te}_{6}$ [4], $\mathrm{A}_{2} \mathrm{Bi}_{8} \mathrm{Se}_{13}(\mathrm{~A}=\mathrm{Rb}, \mathrm{Cs})$ [5], $\mathrm{CsBi}_{3.67} \mathrm{Se}_{6}$ [5] and $\mathrm{BaBi}_{2} \mathrm{Se}_{4}$ [5]. We continued to improve the thermoelectric properties of these materials by composition doping, as in the case of $\beta-\mathrm{K}_{2} \mathrm{Bi}_{8} \mathrm{Se}_{13}$ and $\mathrm{CsBi}_{4} \mathrm{Te}_{6}$. In an effort to explore the ultimate performance of $\mathrm{CsBi}_{4} \mathrm{Te}_{6}$ (a low temperature thermoelectric material), we introduced $\mathrm{PbTe}$ into its layered framework. Consequently, the four new compounds of $\mathrm{CsPbBi}_{3} \mathrm{Te}_{6}(\mathbf{1}), \mathrm{CsPb}_{2} \mathrm{Bi}_{3} \mathrm{Te}_{7}(\mathbf{2}), \mathrm{CsPb}_{3} \mathrm{Bi}_{3} \mathrm{Te}_{8}(\mathbf{3})$ and $\mathrm{CsPb}_{4} \mathrm{Bi}_{3} \mathrm{Te}_{9}$ (4) were discovered by the reactions of $\mathrm{CsBi}_{4} \mathrm{Te}_{6}$ with increasing content of $\mathrm{PbTe}$. The $\mathrm{Pb} / \mathrm{Bi} / \mathrm{Te}$ system was extensively studied for thermoelectric applications in past work [6-10]. The $\mathrm{Pb}$ and $\mathrm{Bi}$ atoms are well known to disorder on the same crystallographic positions due to their similar size and coordination preferences. In general, this results in low thermal conductivity by increasing phonon scattering. The four new compounds adopt novel layered structures built up of anionic slabs with progressively increasing thickness. These anionic slabs can be viewed as fragments excised from $\{\mathrm{PbTe}\}$-type structure with the thickness of 4-,5-, 6- and 7-\{PbTe\} monolayers. This family offers a brand-new homologous series $\mathrm{CsPb}_{\mathrm{m}} \mathrm{Bi}_{3} \mathrm{Te}_{5+\mathrm{m}}(\mathrm{m}=1$ to 4 ) available for structural and thermoelectric investigations. 
Table 1. Summary of Crystallographic Data for the $\mathrm{CsPb}_{\mathrm{m}} \mathrm{Bi}_{3} \mathrm{Te}_{5+\mathrm{m}}$ Compounds

\begin{tabular}{lllll}
\hline Compounds & $\mathbf{1}$ & $\mathbf{2}$ & $\mathbf{3}$ & $\mathbf{4}$ \\
\hline Formula & $\mathrm{CsPbBi}_{3} \mathrm{Te}_{6}$ & $\mathrm{CsPb}_{2} \mathrm{Bi}_{3} \mathrm{Te}_{7}$ & $\mathrm{CsPb}_{3} \mathrm{Bi}_{3} \mathrm{Te}_{8}$ & $\mathrm{CsPb}_{4} \mathrm{Bi}_{3} \mathrm{Te}_{9}$ \\
Crystal Habit & needle & needle & needle & needle \\
a, $\AA$ & $6.3326(6)$ & $4.3456(6)$ & $6.3736(8)$ & $4.4524(6)$ \\
$\mathrm{b}, \AA$ & $28.667(3)$ & $32.476(5)$ & $37.731(5)$ & $42.132(6)$ \\
$\mathrm{c}, \AA$ & $4.3637(4)$ & $12.508(2)$ & $4.4416(6)$ & $12.742(2)$ \\
$\mathrm{V}, \AA^{3}$ & $792.1(2)$ & $1765.2(7)$ & $1068.1(4)$ & $2390.3(9)$ \\
$\mathrm{Z}$ & 4 & 8 & 4 & 8 \\
Space Group & Cmcm & Cmcm & Cmcm & Cmcm \\
Temperature (K) & 293 & 293 & 293 & 293 \\
$\mathrm{R}_{1}{ }^{a}$ & 0.0391 & 0.0410 & 0.0597 & 0.0489 \\
$\mathrm{wR}_{2}{ }^{b}$ & 0.1095 & 0.1179 & 0.1695 & 0.1250
\end{tabular}

${ }^{a} \mathrm{R}_{1}=\sum|| \mathrm{F}_{\mathrm{o}}|-| \mathrm{F}_{\mathrm{c}}\left|/ / \mathrm{V}_{\mathrm{o}}\right|{ }^{b} \mathrm{wR}_{2}=\left[\sum\left[\mathrm{w}\left(\mathrm{F}_{\mathrm{o}}^{2}-\mathrm{F}_{\mathrm{c}}^{2}\right)^{2} / \sum\left[\mathrm{w}\left(\mathrm{F}_{\mathrm{o}}{ }^{2}\right)^{2}\right]^{1 / 2}\right.\right.$

\section{RESULTS AND DISCUSSION}

Crystallographic data for compounds 1, 2, $\mathbf{3}$ and $\mathbf{4}$ are listed in Table 1. They all crystallize in the orthorhombic space group $\mathrm{Cmcm}$. Crystals of the four compounds were initially obtained by the reactions of $\mathrm{CsBi}_{4} \mathrm{Te}_{6}$ and $\mathrm{PbTe}$ with molar ratios of $1 / 1$ for $\mathbf{1}, 1 / 3$ for $2,1 / 4$ for 3 and $1 / 6$ for 4 . The mixtures were heated at $600{ }^{\circ} \mathrm{C}$ and slow cooling to $50{ }^{\circ} \mathrm{C}$. Pure phases can also be prepared by the reactions of $\mathrm{Cs}$ metal and pre-reacted $\mathrm{Pb}-\mathrm{Bi}$-Te mixtures of appropriate ratio.

The layered structures of the four compounds consist of infinite anionic $\left[\mathrm{Pb}_{\mathrm{m}} \mathrm{Bi}_{3} \mathrm{Te}_{5+\mathrm{m}}\right]^{-}$slabs separated with $\mathrm{Cs}^{+}$cations, see Figure 1 . The crystallographically distinct metal sites, $\mathrm{M}$, in the $\left[\mathrm{M}_{\mathrm{m}+3} \mathrm{Te}_{5+\mathrm{m}}\right]^{-}$slab are octahedrally coordinated with Te atoms. The average M-Te distance is 3.173(1) $\AA$, which is very similar to the average Bi-Te distance of $3.18 \AA$ in $\mathrm{CsBi}_{4} \mathrm{Te}_{6}$. Alternatively, the $\left[\mathrm{PbBi}_{3} \mathrm{Te}_{6}\right]^{-}$slab can be viewed as a fragment excised from PbTe-type structure along the [110] direction with a thickness of four $\{\mathrm{PbTe}\}$ monolayers, see Figure 2a. It is interesting to compare and contrast the $\mathrm{CsPbBi}_{3} \mathrm{Te}_{6}$ and $\mathrm{CsBi}_{4} \mathrm{Te}_{6}$ structures since both of them posses a $\mathrm{M}_{4} \mathrm{Te}_{6}$ " type of anionic slabs. $\mathrm{CsBi}_{4} \mathrm{Te}_{6}$ is made of parallel infinite $\left[\mathrm{Bi}_{4} \mathrm{Te}_{6}\right]^{-}$rods arranged side-by-side and linked with $\mathrm{Bi}$-Bi bonds [4]. As some of the $\mathrm{Bi}^{3+}$ ions are replaced by $\mathrm{Pb}^{2+}$ ions to give $\mathrm{CsPbBi}_{3} \mathrm{Te}_{6}, \mathrm{Bi}-\mathrm{Bi}$ bonding is no longer possible, nor necessary, and the $\left[\mathrm{Bi}_{4} \mathrm{Te}_{6}\right]^{-}$slabs reorganize by the cleavage of $\mathrm{Bi}-\mathrm{Bi}$ bonds and formation of new $\mathrm{Bi}(\mathrm{Pb})-\mathrm{Te}$ bonds between the $\mathrm{PbTe}$-type rods generating the infinite slabs of $\left[\mathrm{PbBi}_{3} \mathrm{Te}_{6}\right]^{-}[11]$.

The structure of $\mathrm{CsPb}_{2} \mathrm{Bi}_{3} \mathrm{Te}_{7}(2)$ has thicker $\left[\mathrm{Pb}_{2} \mathrm{Bi}_{3} \mathrm{Te}_{7}\right]^{-}$slabs, as displayed in Figure $1 \mathrm{~b}$. The $\left[\mathrm{Pb}_{2} \mathrm{Bi}_{3} \mathrm{Te}_{7}\right]^{-}$slab is also a fragment excised from PbTe-type structure with $5\{\mathrm{PbTe}\}$ monolayers, that is one monolayer thicker than the slab in 1, Figure 2b. Remarkably, this architecture can sustain thicker anionic slabs to give $\mathrm{CsPb}_{3} \mathrm{Bi}_{3} \mathrm{Te}_{8}(\mathbf{3})$ and $\mathrm{CsPb}_{4} \mathrm{Bi}_{3} \mathrm{Te}_{9}(\mathbf{4})$ structures, Figures 1c and 1d. The anionic slabs in $\mathbf{3}$ and $\mathbf{4}$ 


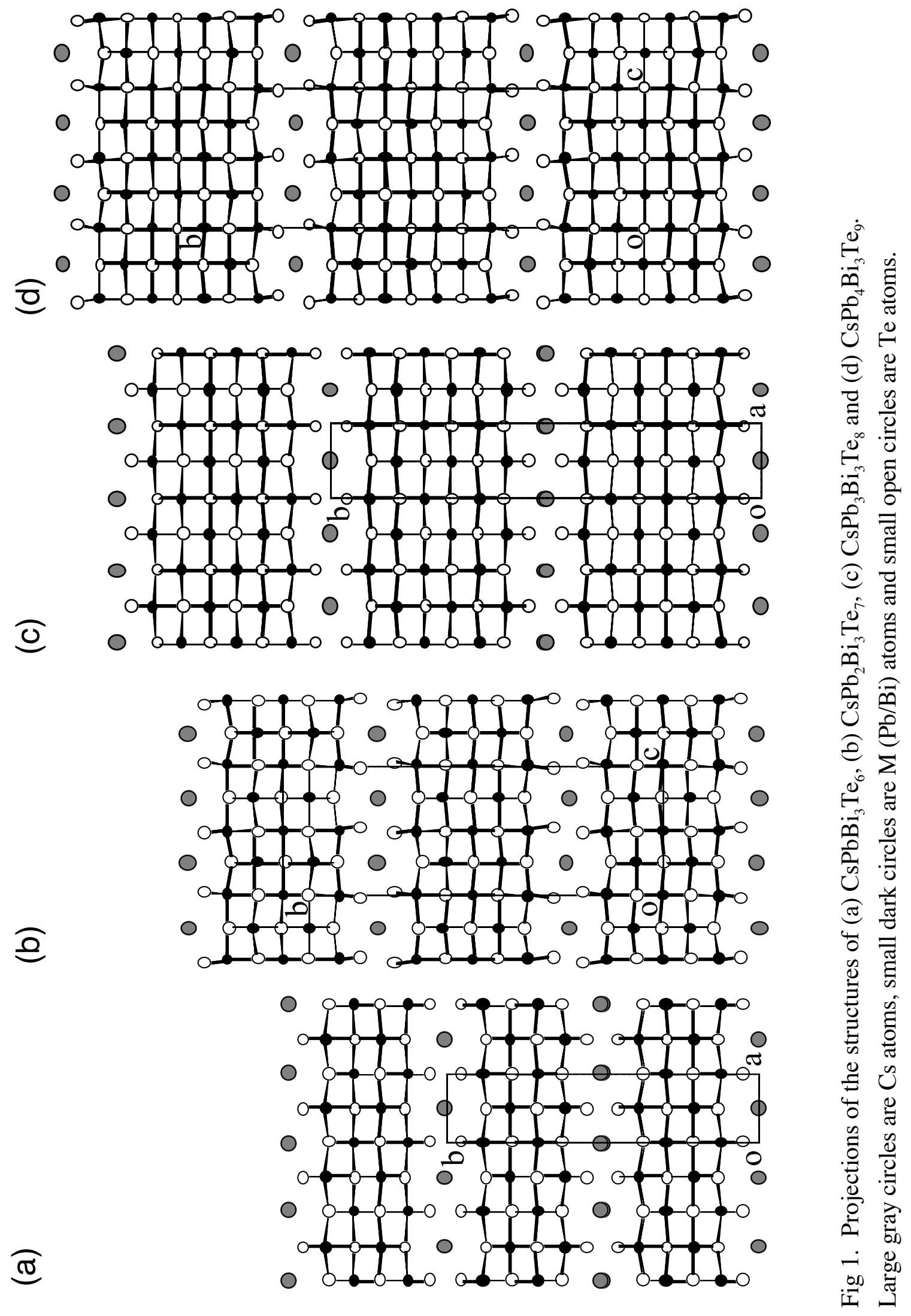

G8.25.3 
are also fragments of the PbTe-type structure with six and seven $\{\mathrm{PbTe}\}$ monolayers, Figures $2 \mathrm{c}$ and $2 \mathrm{~d}$. As a result, the longest $b$ axes, perpendicular to the layers, are correspondingly increased and vary almost linearly with the number of monolayers. A brand-new homologous series $\mathrm{CsPb}_{\mathrm{m}} \mathrm{Bi}_{3} \mathrm{Te}_{5+\mathrm{m}}$ is then revealed by the four layered structures. As indicated by bond-valence calculations, both $\mathrm{Bi}^{3+}$ and $\mathrm{Pb}^{2+}$ ions occupy the $\mathrm{M}$ sites in the four structures [12]. This disordered behavior also occurs in the isostructural $\mathrm{Sn}$ analogs of 1 and 2. In the latter cases with $\mathrm{Sn}$ the $\mathrm{Sn} / \mathrm{Bi}$ disorder was resolved by single-crystal X-ray structural analysis [11].

There are some significant differences in the stacking and fine structural details of the slabs in the four compounds. First, as the slabs stack along the $b$ axis the rows of terminal $\mu_{2}$-Te atoms found on the surfaces of the slabs are arranged in staggered fashion in $\mathbf{1}$ and $\mathbf{3}$, but they are eclipsed in $\mathbf{2}$ and 4. Second, the $\mu_{2}$-Te atom shifts away from its $m 2 m$ site in $\mathbf{1}$ and $\mathbf{3}$ to a $m$ site in $\mathbf{2}$ and $\mathbf{4}$. The repeating units along the $c$ axis in $\mathbf{2}$ and $\mathbf{4}$ are then doubled compared to the corresponding direction in $\mathbf{1}$ and $\mathbf{3}$.

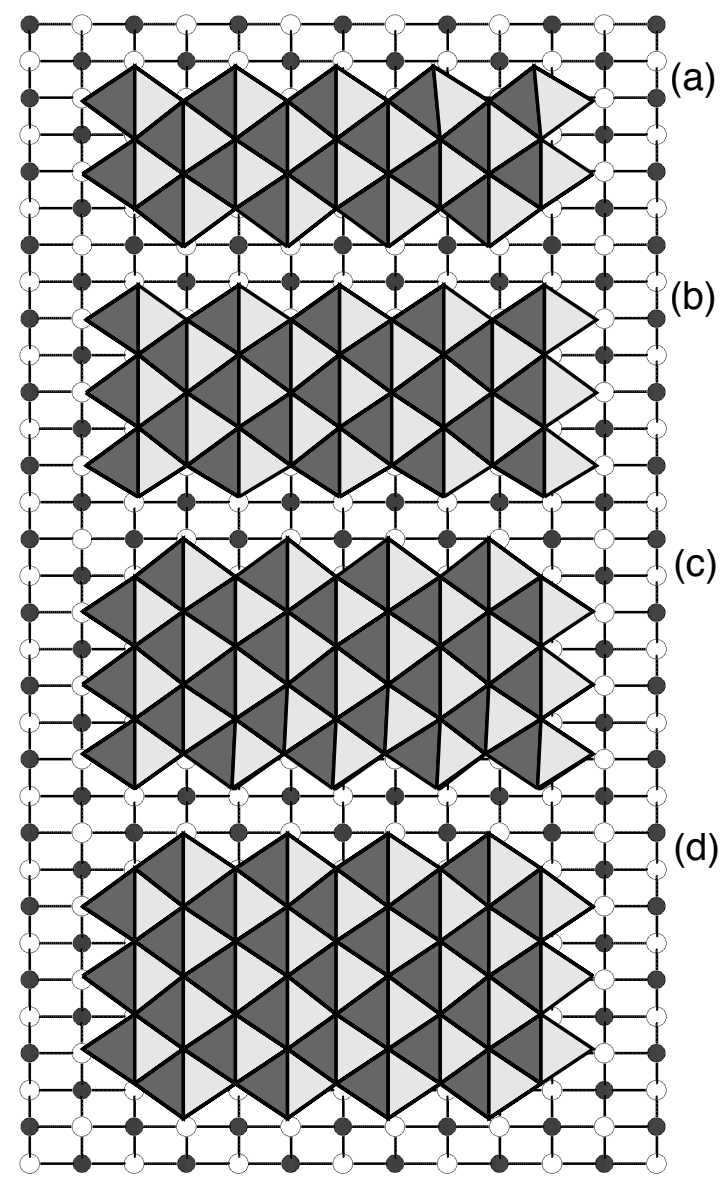

Fig 2. A view of the PbTe structure along the [110] direction. The anionic slabs in structures $\mathbf{1}, \mathbf{2}, \mathbf{3}$ and 4 are fragments excised from this lattice with (a) 4, (b) 5, (c) 6 and (d) $7\{\mathrm{PbTe}\}$ monolayers thick, respectively. 
In the four structures, the Cs cations are surrounded by nine Te atoms and situated around the centers of tricapped trigonal bipyramids. Occupancy refinements showed that the Cs sites were not fully occupied in the four structures. Interestingly, the Cs atom sites are more fully occupied in the structures composed of thicker slabs and the occupancies are $85 \%$ in 1,91\% in 2, $93 \%$ in 3 and $96 \%$ in 4 . The final formulas of four compounds in this homologous series were then adjusted to be Bi-rich compositions for electroneutrality, which are $\mathrm{Cs}_{0.85} \mathrm{~Pb}_{0.85} \mathrm{Bi}_{3.15} \mathrm{Te}_{6}$ of $\mathbf{1}$, $\mathrm{Cs}_{0.91} \mathrm{~Pb}_{1.91} \mathrm{Bi}_{3.09} \mathrm{Te}_{7}$ of $\mathbf{2}, \mathrm{Cs}_{0.93} \mathrm{~Pb}_{2.93} \mathrm{Bi}_{3.07} \mathrm{Te}_{8}$ of $\mathbf{3}$ and $\mathrm{Cs}_{0.96} \mathrm{~Pb}_{3.96} \mathrm{Bi}_{3.04} \mathrm{Te}_{9}$ of $\mathbf{4}$. The isostructural Sn analogues of $\mathbf{1}$ and 2 also gave similarly Cs-deficient stoichiometries, $\mathrm{Cs}_{0.84} \mathrm{Sn}_{0.84} \mathrm{Bi}_{3.16} \mathrm{Te}_{6}$ and $\mathrm{Cs}_{0.88} \mathrm{Sn}_{1.88} \mathrm{Bi}_{3.12} \mathrm{Te}_{7}$, which were determined by single-crystal X-ray diffraction analyses.
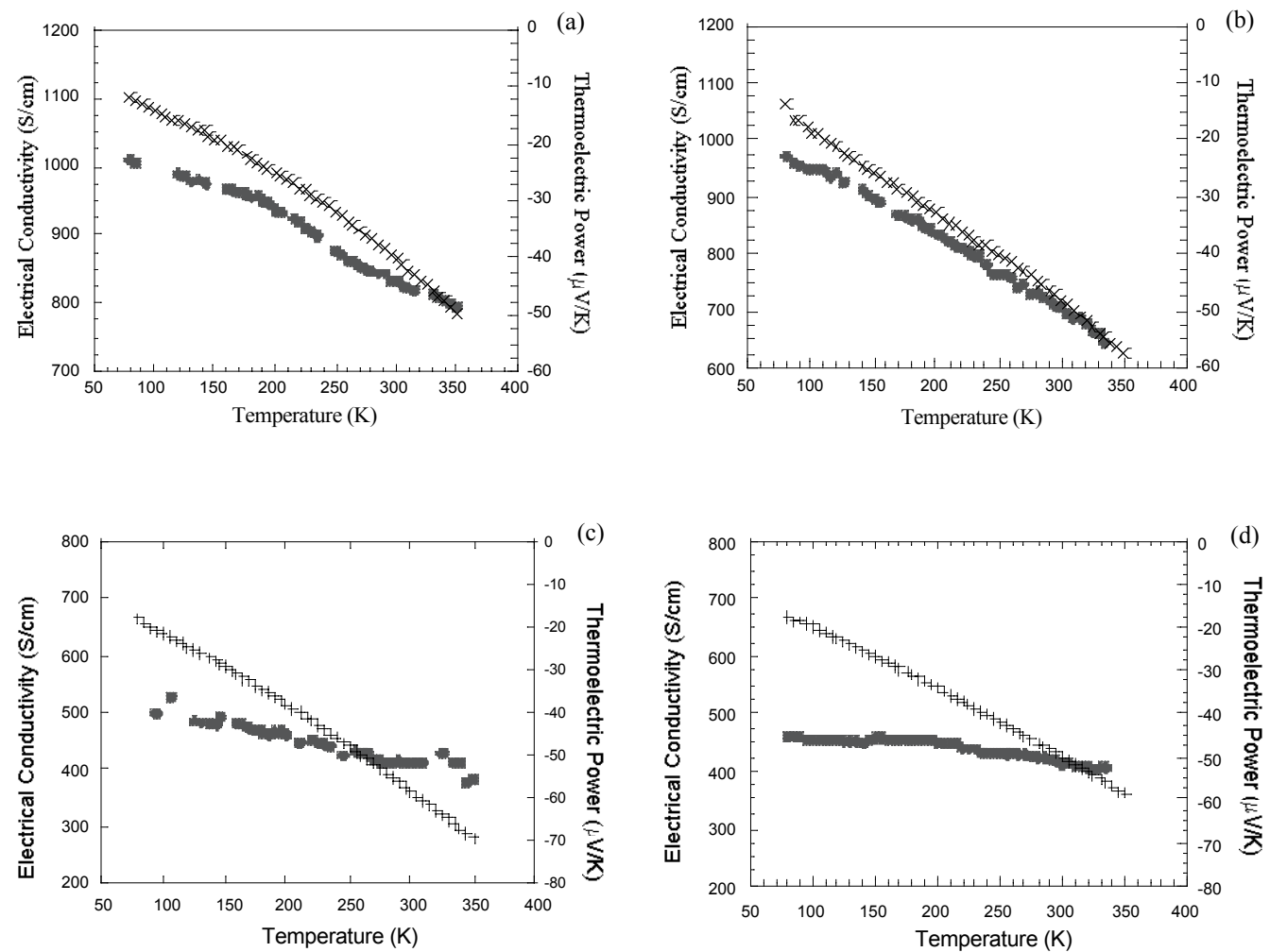

Fig 3. Variable temperature electrical conductivity and thermopower data for oriented polycrystalline ingot samples of (a) $\mathrm{CsPbBi}_{3} \mathrm{Te}_{6}$, (b) $\mathrm{CsPb}_{2} \mathrm{Bi}_{3} \mathrm{Te}_{7}$, (c) $\mathrm{CsPb}_{3} \mathrm{Bi}_{3} \mathrm{Te}_{8}$ and (d) $\mathrm{CsPb}_{4} \mathrm{Bi}_{3} \mathrm{Te}_{9}$. The crosses are thermopower and circles are electrical conductivity.

Charge transport measurements on polycrystalline ingots of the $\mathrm{CsPb}_{\mathrm{m}} \mathrm{Bi}_{3} \mathrm{Te}_{5+\mathrm{m}}(\mathrm{m}=1,2,3$ and 4) compounds show metallic behavior where the electrical conductivity increases as the temperature drops, Figure 3. The conductivity decrease from $1010 \mathrm{~S} / \mathrm{cm}$ at $80 \mathrm{~K}$ to $800 \mathrm{~S} / \mathrm{cm}$ at $350 \mathrm{~K}$ for 1; from $970 \mathrm{~S} / \mathrm{cm}$ at $80 \mathrm{~K}$ to $600 \mathrm{~S} / \mathrm{cm}$ at $350 \mathrm{~K}$ for $2 ; 500 \mathrm{~S} / \mathrm{cm}$ at $80 \mathrm{~K}$ to $410 \mathrm{~S} / \mathrm{cm}$ at $350 \mathrm{~K}$ for 3; and from $460 \mathrm{~S} / \mathrm{cm}$ at $80 \mathrm{~K}$ to $400 \mathrm{~S} / \mathrm{cm}$ at $350 \mathrm{~K}$ for 4 . The values of thermopower 
are $-50 \mu \mathrm{V} / \mathrm{K}$ for $1,-57 \mu \mathrm{V} / \mathrm{K}$ for $2,-70 \mu \mathrm{V} / \mathrm{K}$ for 3 and $-50 \mu \mathrm{V} / \mathrm{K}$ for 4 at $350 \mathrm{~K}$. The relatively low thermopower and metallic like temperature dependence of conductivity indicate that $\mathrm{CsPb}_{\mathrm{m}} \mathrm{Bi}_{3} \mathrm{Te}_{5+\mathrm{m}}$ materials are heavily doped. This is consistent with their Bi-rich non-stoichiometric nature suggested by the elemental analysis and crystallographic refinement. A Bi-rich stoichiometry will result in electron carrier excess in these materials giving rise to negative thermopower as $\mathrm{Bi}$ possesses an extra electron compared to $\mathrm{Pb}$ [11]. Remarkably, the thermal conductivities at room temperature were low for the four layered compounds. They are $1.8 \mathrm{~W} / \mathrm{m} \cdot \mathrm{K}$ for $\mathrm{CsPbBi}_{3} \mathrm{~T}_{6}, 1.6 \mathrm{~W} / \mathrm{m} \cdot \mathrm{K}$ for $\mathrm{CsPb}_{2} \mathrm{Bi}_{3} \mathrm{Te}_{7}$ and $1.5 \mathrm{~W} / \mathrm{m} \cdot \mathrm{K}$ for $\mathrm{CsPb}_{3} \mathrm{Bi}_{3} \mathrm{Te}_{8}$ and $\mathrm{CsPb}_{4} \mathrm{Bi}_{3} \mathrm{Te}_{9}$. The heavy atoms involved and long-period crystal structures play an important role in producing low thermal conductivities in the $\mathrm{CsPb}_{\mathrm{m}} \mathrm{Bi}_{3} \mathrm{Te}_{5+\mathrm{m}}$ family.

\section{CONCLUSIONS}

The four layered compounds, derived from $\mathrm{CsBi}_{4} \mathrm{Te}_{6}$ and $\mathrm{PbTe}$, enrich the structural chemistry of multinary bismuth telluride systems and bring new groups of phases for thermoelectric studies. The compounds in this series are characterized with low thermal conductivity comparable to that of $\mathrm{Bi}_{2} \mathrm{Te}_{3}$ and $\mathrm{CsBi}_{4} \mathrm{Te}_{6}$. Based on this information, we will continue our efforts to improve their thermoelectric properties by compositional doping and by preparing additional analogs.

\section{ACKNOWLEDGMENTS}

Financial support from the Office of Naval Research and DARPA (Grant No. N00014-01-10728) is gratefully acknowledged.

\section{REFERENCES}

1. T. J. McCarthy, S. P. Ngeyi, J. H. Liao,D. DeGroot, T. Hogan, C. R. Kannewurf, Kanatzidis, M. G. Chem. Mater. 5, 331-340 (1993).

2. D. Y. Chung, K. S. Choi, L. Iordanidis, M. G. Kanatzidis, J. L. Schindler, P. W. Brazis, C. R. Kannewurf, B. Chen, S. Hu, C. Uher Chem. Mater. 9, 3060-3071 (1997).

3. D. Y. Chung, S. Jobic, T. Hogan, C. R. Kannewurf, R. Brec, J. Rouxel, M. G. Kanatzidis J. Am. Chem. Soc. 119, 2505-2515 (1997).

4. $\quad$ Chung, D. Y.; Hogan, T.; Brazis, P. W.; Rocci-Lane, M.; Kannewurf, C. R.; Bastea, M.; Uher, C.; Kanatzidis, M. G. Science 287, 1024-1027 (2000).

5. L. Iordanidis, P. W. Brazis, T. Kyratsi, J. Ireland, M. Lane, C. R. Kannewurf, W. Chen, J. S. Dyck, C. Uher, N. A. Ghelani, T. Hogan, M. G. Kanatzidis Chem. Mater. 13, 622-633 (2001).

6. T. B. Zhukova, A. I. Zaslavskii Sov. Phys. Crystallogr. 16, 796-800 (1971).

7. R. Chami, G. Brun, J. C. Tedenac Rev. Chim. Miner. 20, 305-313 (1983).

8. T. B. Zhukova, A. I. Zaslavskii Inorg. Mater. 12, 467-469 (1976).

9. N. S. Golovanova, V. P. Zlomanov, O. I. Tananaeva Inorg. Chem. 19, 669-672 (1983).

10. I. I. Petrov, R. M. Imamov Sov. Phys. Crystallogr. 14, 593-596 (1969).

11. K. F. Hsu, D. Y. Chung, S. Lal, A. Mrotzek, T. Kyratsi, T. Hogan, M. G. Kanatzidis J Am. Chem. Soc. 2002, in press.

12 I. D. Brown J. Appl. Cryst. 29, 479-480 (1996). 